\title{
The contrasting effects of diazepam and yohimbine on conditioned defensive burying in rats
}

\author{
AKIRA TSUDA, YOSHISHIGE IDA, and MASATOSHI TANAKA \\ Kurume University School of Medicine, Kurume, Japan
}

\begin{abstract}
The conditioned defensive burying (CDB) paradigm consists of placing rats in a test chamber with wood shavings on the floor, shocking them with a shock prod, and recording the time each rat spends in a burying response to the prod during a 15 -min test session. This experiment revealed contrasting effects of the anxiolytic agent, diazepam $(0.5$ and $2 \mathrm{mg} / \mathrm{kg}$, i.p.), and the anxiogenic agent, yohimbine $(0.5$ and $2 \mathrm{mg} / \mathrm{kg}$, i.p.), on CDB of male hooded rats. During the test session, diazepam-injected rats spent significantly less time engaged in CDB than did vehicle-injected rats. On the other hand, yohimbine-injected rats spent significantly more time burying than did the vehicle-injected rats, and did so in a dose-dependent fashion. Twenty-four hours later when a retention session was conducted without any additional shocks and injections, both the facilitative effects of yohimbine and the suppressive effects of diazepam on the CDB were still observed in terms of duration, number, and latency of burying, as well as in the height of piles accumulated. These results indicate that the postshock CDB could be differentiately affected by anxiolytic and anxiogenic agents. The CDB paradigm might represent an appropriate model for studying the pharmacological analysis and neuronal mechanisms of anxiety and/or fear in animals.
\end{abstract}

A number of animal behavioral models of fear and/or anxiety have been developed in the past 3 decades. The models listed below have provided important information concerning the potential anxiolytic actions and neuropharmacological mechanisms involved in the responses of anxiety and/or fear: conditioned suppression (Geller \& Seifter, 1960; Vogel, Beer, \& Clody, 1971), social interaction (File, 1980), potentiated startle (Davis, 1979), and exploratory activity (Crawley, 1981; Yamamoto \& Ueki, 1987). Some of these models, however, do have some shortcomings. These include expensive experimental setup, lengthy periods of experimentation, and validity of data interpretation.

In a recent review paper, Treit (1985a) described a novel test of anxiety in animals-the conditioned defensive burying (CDB) paradigm. In the CDB paradigm, rats are placed in a test chamber with bedding material on the floor and shocked with a wire-wrapped prod mounted on one end wall of the chamber; the amount of time the rats display burying responses (i.e., pushing and spraying the bedding material with snout and forepaws toward and over the shock prod) is recorded (Pinel \& Treit, 1978). Treit, Pinel, and Fibiger (1981) first reported that such anxio-

\footnotetext{
This research was supported in part by a Grant-in-Aid for Encouragement of Young Scientists (No. 61710096) to A. Tsuda from the Ministry of Education, Science and Culture of Japan and by a research rrant from the Pharmacopsychiatry Research Foundation to M. Tanaka. We express our gratitude to Gary B. Glavin of the Department of Pharmacology and Therapeutics, University of Manitoba, Winnipeg, Canada, for his kind help in preparing this English draft. Requests for reprints should be addressed to Akira Tsuda, Department of Pharamacology, Kurume University School of Medicine, Kurume 830, Japan.
}

lytic drugs as diazepam selectively suppressed the CDB in a dose-dependent fashion, whereas such nonanxiolytic drugs as d-amphetamine had no effect on the CDB. Treit (1985b) conducted subsequent studies to show that the suppression of the CDB by diazepam was produced through anxiolytic, rather than analgesic, effects. Blampied and Kirk (1983) demonstrated the suppressive effects of diazepam on the $\mathrm{CDB}$, and provided further evidence that these effects did not reflect a decrease in spontaneous activity.

Although these reports suggest that the CDB paradigm appears to be a useful and simple method for the preclinical evaluation of anxiolytic drugs, a problem with such research is that the CDB paradigm has not been investigated to detect anxiogenic drug effects. If $\mathrm{CDB}$ does reflect fear and/or anxiety, then it should be potentiated by drugs that are thought to induce fear and/or anxiety. To date, however, only manipulations of anxiolytic drugs have been specifically conducted to produce suppressive effects on the CDB (Blampied \& Kirk, 1983; Treit, 1985b; Treit et al., 1981).

The anxiogenic compound that we used in this experiment was yohimbine, an $\alpha_{2}$-adrenergic antagonist. It is one of a well-known group of agents that cause druginduced anxiety in animals (Browne, 1981) and humans (Charney, Heninger, \& Redmond, 1983). Yohimbine is also found to produce increases in noradrenaline turnover in the rat's brain (Oguchi et al., 1987). In earlier studies, we suggested that increased activity in brain noradrenergic neuronal systems is related to indications of such "hyperemotionality" as fear or anxiety (Ida, Tanaka, Tsuda, Tsujimaru, \& Nagasaki, 1985; Tanaka et al., 
1983). The anxiolytic compound that we used in this study was diazepam, a benzodiazepine derivative. It is not only a prototypical anxiolytic agent, but was also found to inhibit postshock CDB in a CDB paradigm (Blampied \& Kirk, 1983; Treit, 1985b; Treit et al., 1981). Accordingly, this study was designed to determine whether diazepam, as an anxiolytic drug, would suppress the CDB, and whether yohimbine, as an anxiogenic drug, would potentiate this behavior.

\section{METHOD}

\section{Subjects}

Thirty-five male PVG/c hooded rats purchased from the Seiwa Animal Laboratory (Chikuzyou-gun, Fukuoka) served as subjects. The subjects were approximately 120 days old $(200-250 \mathrm{~g})$ at the beginning of the experiment. All animals were housed in groups of 3 to 4 in standard propylene cages, with food and water available on a free-feeding basis. Room temperature was controlled at $24^{\circ} \pm 1^{\circ} \mathrm{C}$ (relative humidity $50 \% \pm 10 \%$ ), and daylight conditions were artificially maintained between 7 a.m. and 7 p.m. All experimental procedures were carried out between $10 \mathrm{a} . \mathrm{m}$. and 2 p.m.

\section{Apparatus}

A rectangular transparent acrylic plastic box $(45 \mathrm{~cm}$ long $x$ $30.5 \mathrm{~cm}$ wide $\times 44 \mathrm{~cm}$ high) was used as the testing chamber. The floor of the chamber consisted of white flake bedding material $5 \mathrm{~cm}$ deep (Charles River Japan, Inc., Atsugi, Kanagawa). A black carbonate prod $(6.5 \mathrm{~cm}$ long $\times 1.2 \mathrm{~cm}$ diameter) that was wrapped with two uninsulated wires was mounted in the center of an end wall of the testing chamber, $2 \mathrm{~cm}$ above the bedding material. The aversive stimulus generated by a shock generator-scrambler (SGS001, Muromachi Kikai Co., Ltd. Tokyo) was delivered to the wires of the shock prod.

\section{Procedure}

Habituation. Habituation to the testing chamber without the shock prod was done in squads of 3 or 4 rats for $30-$ min periods on 3 consecutive days. On Day 4 , the shock prod was attached to the chamber, and the rats were placed individually in the center of the chamber for $15 \mathrm{~min}$. Since this control session served as a burying baseline period, no shock was given when the rat touched the shock prod.

Drug administration. On Day 5, the rats were assigned $(n=7)$ to an injection condition on the basis of the duration of spontaneous burying episodes displayed in the control session, and injected i.p. with diazepam, 0.5 or $2.0 \mathrm{mg} / \mathrm{kg}$, yohimbine, 0.5 or $2.0 \mathrm{mg} / \mathrm{kg}$, or an equivalent volume $(0.2 \mathrm{ml} / 100 \mathrm{~g})$ of $0.3 \%$ carboxymethyl cellulose sodium vehicle (CMC). Diazepam was suspended in $0.3 \%$ CMC; yohimbine was dissolved in $0.9 \%$ saline.

Shock administration (test session). After $15 \mathrm{~min}$, the subjects were placed individually into the chamber with the shock prod. When the rat first touched the shock prod with a forepaw, the experimenter initiated a brief shock (4-mA shock intensity), which terminated with the withdrawal of the paw from the shock prod. The rat then remained confined to the chamber without additional shock for a 15-min postshock burying test session.

Retention. On Day 6, the rat was placed again in the chamber for $15 \mathrm{~min}$. Neither drugs nor shocks were given during this retention session.

Behavioral observation. For each session, $\mathrm{CDB}$ related responses were observed by two independent observers, using standard timers and event counters to record the number of contacts with the shock prod, the latency to initiate the first $\mathrm{CDB}$, frequency of $\mathrm{CDB}$ occurrence, and amount of time spent in CDB. The CDB behavior was defined as a series of stereotyped sequences in which the rat moved toward the shock prod, pushing and spraying a pile of bedding material at the prod with rapid movements of the snout and forepaws (Pinel \& Teit, 1978). The number of approach-avoidance responses (defined as the rat's approaching the shock prod in an extended position and then suddenly withdrawing from it) were also observed. At the end of each session, the heights of piles of bedding within $10 \mathrm{~cm}$ of the prod were measured.

\section{Statistical Analyses}

Data were analyzed by a two-way (drug $\times$ session) analysis of variance (ANOVA) and subsequent Tukey's HSD pairwise comparisons.

\section{RESULTS}

The two observers showed a high degree of agreement in terms of the amount of time $[r(28)=0.92, p<.01]$ and frequency $[r(28)=0.86, p<.01]$ that each rat engaged in CDB. Figure 1 depicts time spent and number of CDBs during the test and retention sessions. An ANOVA of burying-duration data revealed significant main effects of session $[F(1,60)=7.10, p<.05]$ and drug $[F(4,60)=16.66, p<.01]$. Tukey's $H S D$ post hoc comparisons $(\alpha<.05)$ indicated that the vehicle- and yohimbine-treated rats engaged in more CDB during the test session than they did in the control session. The amount of CDB displayed by the diazepam-treated rats at two doses during the test session was the same as the amount displayed during the control session. During the test session, the yohimbine-treated rats spent significantly more time and the diazepam-treated rats spent significantly less time in CDB than did the vehicle-treated rats. The rats given yohimbine at $0.5 \mathrm{mg} / \mathrm{kg}$ had lower CDB levels in the retention session than they did in the retention session. However, the rats given yohimbine at $2 \mathrm{mg} / \mathrm{kg}$ still spent significantly more time in CDB in the retention session than did the vehicle-treated rats. The diazepamtreated rats showed less CDB during the retention session.

An ANOVA of the number of burying episodes also yielded a significant drug effect $[F(4,60)=16.01$, $p<.01]$. Tukey's $H S D$ post hoc comparisons $(\alpha<.05)$ indicated that vehicle- and yohimbine-treated rats showed more frequent $\mathrm{CDB}$ in the test session than they did in the control session. The yohimbine-treated rats dosedependently had more and the diazepam-treated rats had significantly fewer elicitations of postshock CDB than did the vehicle-treated rats. The vehicle-treated rats and the rats given yohimbine at $0.5 \mathrm{mg} / \mathrm{kg}$ significantly reduced their frequency of $\mathrm{CDB}$ in the retention session. However, the levels of CDB for all yohimbine-treated rats still remained significantly higher than those of the vehicletreated rats.

Table 1 summarizes the various measures of CDBrelated responses as a function of drug treatments and sessions. These measures were analyzed by separate twoway ANOVAs. With respect to duration of CDB per response and number of touches of the shock prod, neither sessions nor drug effects were significant. For the first CDB, diazepam-treated rats showed longer latency and yohimbine-treated rats showed shorter latency in each test and retention session $[F(4,60)=20.46, p<.01]$. The 

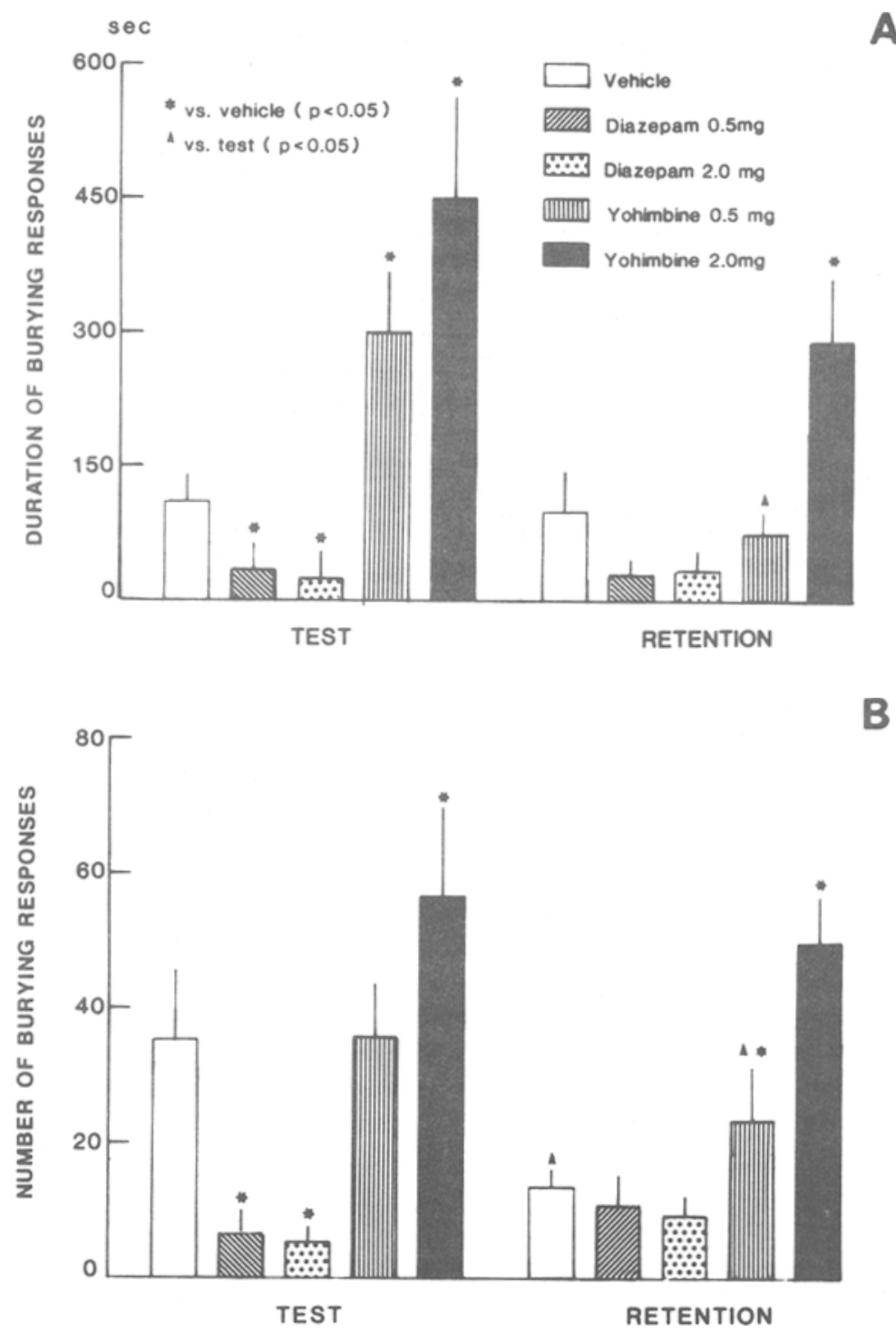

Figure 1. Mean ( $\pm S E M$ ) duration (upper panel, A) and number (lower panel, B) of conditioned defensive burying responses in test and retention sescions for rats given an injection of vehicle, diazepam 0.5 and $2 \mathrm{mg} / \mathrm{kg}$, or yohimbine 0.5 and $2 \mathrm{mg} / \mathrm{kg}$.

drugs showed significant main effects on the height of pile $[F(4,60)=8.00, p<.01]$. The mean height of pile for the diazepam-treated rats in the test session was less than that of the vehicle-treated rats, whereas the yohimbinetreated rats piled significantly more bedding material. There was a significant session effect only on the number of approach-avoidance responses $[F(1,60)=5.52$, $p<.05]$. Irrespective of drug treatments, each rat had slightly more approach-avoidance respones in the retention session than they did in the test session.

\section{DISCUSSION}

The present study showed that the CDB paradigm can detect the contrasting effects of anxiolytic activity induced by diazepam, a benzodiazepine derivative, and anxiogenic activity induced by yohimbine, a prototypical $\alpha_{2}$ adrenergic receptor blocker. Yohimbine potentiated more shock-induced CDB than did the vehicle, while diazepam significantly suppressed the CDB. It has been hypothesized that the CDB elicited by a single shock experience reflects defensive behavior against an aversive source (i.e., shock prod), and the CDB is thus motivated by a negative motivational state of fear and/or anxiety (Pinel \& Treit, 1978; Pinel \& Wilkie, 1983).

The present results indicate that pretreatment with diazepam reduced the duration and frequency of CDB and suppressed burying-related responses (e.g., latency of burying, height of pile, number of approach-avoidance behavior, etc.), which agrees with the results given in 
Table 1

Summary $( \pm S E M)$ of Conditioned Defensive

Burying-Related Responses

\begin{tabular}{|c|c|c|c|c|c|}
\hline Treatment & $\begin{array}{c}\text { Duration of } \\
\text { Burying per } \\
\text { Response } \\
(\mathrm{sec})\end{array}$ & $\begin{array}{c}\text { Latency of } \\
\text { Burying } \\
\text { (sec) }\end{array}$ & $\begin{array}{c}\text { Height of } \\
\text { Pile } \\
\text { (cm) }\end{array}$ & $\begin{array}{l}\text { Number of } \\
\text { Approach- } \\
\text { Avoidance } \\
\text { Responses }\end{array}$ & $\begin{array}{c}\text { Number } \\
\text { of } \\
\text { Touches }\end{array}$ \\
\hline \multicolumn{6}{|c|}{ Test Session } \\
\hline $\begin{array}{l}\text { Vehicle } \\
\text { Diazepam } 0.5 \mathrm{mg} / \mathrm{kg} \\
\text { Diazepam } 2.0 \mathrm{mg} / \mathrm{kg} \\
\text { Yohimbine } 0.5 \mathrm{mg} / \mathrm{kg} \\
\text { Yohimbine } 2.0 \mathrm{mg} / \mathrm{kg}\end{array}$ & $\begin{array}{r}3.7 \pm 0.8 \\
3.4 \pm 1.2 \\
2.7 \pm 1.2 \\
10.1 \pm 4.2 \\
8.2 \pm 2.7\end{array}$ & $\begin{array}{l}104.0 \pm 51.7 \\
596.9 \pm 118.4^{*} \\
620.7 \pm 123.4^{*} \\
17.0 \pm 6.2^{*} \\
20.4 \pm 11.9^{*}\end{array}$ & $\begin{array}{r}9.6 \pm 0.8 \\
7.2 \pm 1.1^{*} \\
6.9 \pm 1.1^{*} \\
11.4 \pm 1.1^{*} \\
10.9 \pm 1.0^{*}\end{array}$ & $\begin{array}{l}3.6 \pm 0.4 \\
2.9 \pm 0.7 \\
0.9 \pm 0.3^{*} \\
3.1 \pm 0.7 \\
3.4 \pm 0.6\end{array}$ & $\begin{array}{l}1.3 \pm 0.2 \\
1.4 \pm 0.5 \\
1.6 \pm 0.3 \\
1.3 \pm 0.3 \\
1.1 \pm 0.1\end{array}$ \\
\hline \multicolumn{6}{|c|}{ Retention Session } \\
\hline $\begin{array}{l}\text { Vehicle } \\
\text { Diazepam } 0.5 \mathrm{mg} / \mathrm{kg} \\
\text { Diazepam } 2.0 \mathrm{mg} / \mathrm{kg} \\
\text { Yohimbine } 0.5 \mathrm{mg} / \mathrm{kg} \\
\text { Yohimbine } 2.0 \mathrm{mg} / \mathrm{kg}\end{array}$ & $\begin{array}{l}4.3 \pm 1.8 \\
3.5 \pm 0.6 \\
3.4 \pm 0.5 \\
3.1 \pm 1.0 \\
5.5 \pm 0.8\end{array}$ & $\begin{array}{l}128.4 \pm 37.2 \\
393.9 \pm 97.2^{*} \\
385.1 \pm 133.1^{*} \\
36.0 \pm 21.2^{*} \\
11.0 \pm 8.1^{*}\end{array}$ & $\begin{array}{c}7.0 \pm 1.4 \dagger \\
7.5 \pm 0.7 \\
8.0 \pm 0.6 \\
8.4 \pm 0.9 \ddagger \\
11.9 \pm 1.0^{*}\end{array}$ & $\begin{array}{l}5.2 \pm 1.5 \dagger \\
4.6 \pm 1.5 \dagger \\
3.3 \pm 1.1 \ddagger \\
4.5 \pm 1.2 \dagger \\
4.3 \pm 2.4\end{array}$ & $\begin{array}{l}1.5 \pm 1.0 \\
1.3 \pm 0.8 \\
1.0 \pm 0.7 \\
2.0 \pm 0.8 \\
1.8 \pm 0.6\end{array}$ \\
\hline
\end{tabular}

*Significantly different from respective vehicle $(p<.05)$. † Significantly different from test session

$(p<.05) . \quad \ddagger$ Significantly different from respective vehicle $(p<.05)$ and from test session $(p<.05)$.

previous reports (Blampied \& Kirk, 1983; Treit, 1985b; Treit et al., 1981). The CDB paradigm was also very sensitive to the effects of yohimbine. Yohimbine caused the rats to spend significantly more time engaged in $\mathrm{CDB}$, induced them to accumulate more bedding material around the shock prod, and shortened the latency of the CDB. Yohimbine, an $\boldsymbol{\alpha}_{\mathbf{2}}$-adrenergic receptor blocker, is known to produce anxiety-like effects, including agitation in humans (Charney et al., 1983), and an increase in struggling in rats, as measured by the modified forced swim procedure (Nishimura, et al., 1987). To our knowledge, this is the first report showing that the CDB paradigm is capable of detecting anxiogenic drug effects. In fact, Treit (1987) recently failed to demonstrate anxiogenic effects of such $\gamma$-amino-butyric acid/benzodiazepine receptor complex agents as picrotoxin, pentylenetetrazol, Ro-151788 , or CGS 8216.

The CDB paradigm might be viewed as a useful method for screening anxiety-related drugs in rats with respect to the simplicity and reliability of a particular form of aversive learning (i.e., a product of one-trial associative learning between an unconditioned aversive stimulus and a neutral stimulus in a laboratory setting) that is important for the survival of rodents in a natural setting (Pinel \& Wilkie, 1983). Treit et al. (1981) originally reported that the CDB paradigm fulfilled the pharmacological criteria of dose-dependent sensitivity, relative potency, and selectivity on the basis of the specific suppressive effects of anxiolytic agents on the CDB.

Nevertheless, the extent to which the CDB paradigm is differentially sensitive to anxiolytic agents is questionable, because such psychotropic drugs as antipsychotics, antidepressants, and central nervous system (CNS) stimulants often produce the same behavioral pattern as do anxiolytic drugs. Davis, Whiteside, Dickson, Thomas, and Heck (1981) found that chlorpromazine, an antipsy- chotic, had suppressive effects on CDB comparable to those produced by anxiolytics, with similar sedative actions and occurrences of catalepsy. An earlier study (Tsuda et al., 1987) reported that both the antipsychotic haloperidol and the CNS stimulant methylphenidate had the same suppressive effects on CDB in mice as did the anxiolytic diazepam, while the antidepressant amitriptyline had no appreciable effects. Further studies are required to dissociate the suppressive effects of anxiolytics on CDB from those of other psychotropic agents in terms of the differential sensitivity of the CDB paradigm, although a previous study has demonstrated that the suppressive effects of chlorpromazine could be dissociated from those of diazepam by increasing the intensity of the aversive shock (Treit et al., 1981).

In the present experiment, the inhibitory effect of diazepam and the facilitative effect of yohimbine on the CDB observed during the test session (original conditioning) were observed again during the retention session (extinction process), with the exception of yohimbine at $0.5 \mathrm{mg} / \mathrm{kg}$. These findings appear compatible with Davidson and Lucki's (1987) finding that yohimbine could produce a lasting change in the baseline level of anxiety in the presence of an aversive stimulus. The results of this experiment also reveal that the CDB displayed by the rats treated with the vehicle and yohimbine at $0.5 \mathrm{mg} / \mathrm{kg}$ decreased rapidly in the retention session, which was the same as the test session but unaccompanied by shock. However, the performance of these rats was robust enough to be similar to that reported by Treit et al. (1981). Allowing rats to engage in CDB immediately after presentation of shock may cause a lessening of the intensity and/or duration of this behavior in subsequent extinction sessions, relative to the case in which rats are not reexposed to the chamber until the first test session $24 \mathrm{~h}$ later (Davis et al., 1981). Recently, we reported finding very 
similar and readily extinguishing responses under the former experimental setting (Tsuda, Ida, \& Tanaka, 1988).

Both anxiolytics and anxiogenics differentially modified not only the elicitation of postshock CDB but also other defensive behaviors in the CDB paradigm. The rats displayed such defensive responses as burying, freezing, and escaping to the fear-eliciting stimulus in a CDB situation (Tsuda et al., 1988). In the present experiment, diazepam produced a suppression of CDB but an increase of passive avoidance (e.g., freezing without access to the shock prod), whereas yohimbine produced a facilitation of the CDB but a suppression of passive avoidance, as indicated by the measurements of burying-related responses listed in Table 1. Treit, LoLordo, and Armstrong (1986) recently found that diazepam-treated rats displayed less $\mathrm{CDB}$, but, paradoxically, more passive avoidance behavior, than did vehicle-treated controls. These findings raise the question of which classes of defensive responses are dominant in the defense-response network for the rat in a CDB situation. It seems that environmental constraints, as well as the actions of drugs, modulate the hierarchy of a rat's defensive repertoire.

In conclusion, the present study extended the pharmacological validation of the CDB paradigm as an appropriate model for studying anxiety in rats, revealing that it can differentially detect the suppressive activity of nonsedating doses of the anxiolytic drug, diazepam, and the facilitative activity of nonalgesic doses of the anxiogenic drug, yohimbine.

\section{REFERENCES}

BlampIed, N. M., \& KiRK, R. C. (1983). Defensive burying: Effects of diazepam and oxprenolol measured in extinction. Life Sciences, 33, 695-699.

BrowNe, R. G. (1981). Anxiolytics antagonize yohimbine's discriminative stimulus properties. Psychopharmacology, 74, 245-249.

Charney, D. S., Heninger, G. R., \& Redmond, D. E., JR.(1983). Yohimbine induced anxiety and increased noradrenergic function in humans: Effects of diazepam and clonidine. Life Sciences, 33, 19-29.

Crawley, J. N. (1981). Neuropharmacologic specificity of a simple animal model for the behavioral actions of benzodiazepines. Phar macolgy, Biochemistry \& Behavior, 15, 696-699.

DAVIDSON, T. L., LUCKI, I. (1987). Long-term effects of yohimbine on behavioral sensitivity to a stressor. Psychopharmacology, 92, 35-41.

DAvIS, M. (1979). Diazepam and flurazepam: Effects on conditioned fear as measured with the potentiated startle paradigm. Psychopharmacology, 62, 1-7.

Davis, S. F., Whiteside, D. A., Dickson, V. A., Thomas, R. L., \& HECK, D. G. (1981). Conditioning and retention of defensvie burying as a function of Elavil and Thorazine injection. Bulletin of the Psychonomic Society, 17, 107-110.
FILE, S. (1980). The use of social interactions as a method for detecting anxiolytic activity of chlordiazepoxide-like drugs. Joumal of Neuroscience Methods, 2, 219-238.

Geller, 1., Seifter, J. (1960). The effects of meprobamate, barbiturates. $d$-amphetamine and promazine on experimentally induced conflict in the rat. Psychopharmacologia, 1, 482.492.

Ida, Y., Tanaka, M., Tsuda, A., Tsujimaru, S., \& Nagasaki, N (1985). Attenuating effect of diazepam on stress-induced increases in noradrenaline turnover in specific brain regions of rats: Antagonism by Ro-15-1788. Life Sciences, 37, 2491-2498.

Nishimura, H., Tsuda, A., Oguchi, M., Shirao, I., IDa, Y., \& TANAKA, M. (1987). Effects of rope-suspending and drug administration (yohimbine, diazepam) on behavior in forced swimming rats. Japanese Journal of Pharmacology, 43(Suppl.), 220.

Oguchi, M., Ida, Y., Tsuda, A., Shirao, I., Gondoh, Y.. \& TANAKA, M. (1987). Effects of diazepam on yohimbine-induced increases in noradrenaline turnover in rat brain. Japanese Journal of Pharmacology, 43(Suppl.), 268.

Pinel, J. P. J., \& Treit, D. (1978). Burying as a defensive response in rats. Journal of Comparative \& Physiological Psychology, 92. 708-712.

Pinel, J. P. J., \& WiLkIE, D. M. (1983). Conditioned defensive burying: A biological and cognitive approach to avoidance learning. In R. L. Mellgren (Ed.), Animal cognition and behavior (pp. 285-318). New York: North-Holland

Tanaka, M., Kohno, Y., Tsuda, A., Nakagawa, R., Ida, Y., IImori, K., Hoaki, Y., \& Nagasaki, N. (1983). Differential effects of morphine on noradrenaline release in brain regions of stressed and non-stressed rats. Brain Research, 275, 105-115.

TrEIT, D. (1985a). Animal models for the study of anti-anxiety agents: A review. Neuroscience \& Biobehavioral Reviews, 9, 203-222.

Treit, D. (1985b). The inhibitory effect of diazepam on defensive burying: Anxiolytic vs. analgesic effects. Pharmacology, Biochemistry \& Behavior, 22, 47-52.

Treit, D. (1987). Ro 15-1788, CGS 8216, picrotoxin, and pentylenetetrazol: Do they antagonize anxiolytic drug effects through an anxiogenic action? Brain Research Bulletin, 19, $401-405$.

Treit, D., LoLordo, V. M., \& ARMSTrong, D. E. (1986). The effects of diazepam on "fear" reactions in rats are modulated by environmental constaints on the rat's defensive repertoire. Pharmacology, Biochemistry \& Behavior, 25, 561-565.

Treit, D., Pinel, J. P. J., Fibiger, H. C. (1981). Conditioned defensive burying: A new paradigm for the study of anxiolytic agents. Phar macology, Biochemistry \& Behavior, 15, 619-626.

TsudA, A., IDA, Y., TANAKA, M. (1988). Behavioral field analysis in two strains of rats in a conditioned defensive burying paradigm. Animal Learning \& Behavior, 16, 354-358.

Tsuda, A., Satoh, H., Shirao, I., OGuchi, M., Nishimura, H., \& TANAKA, M. (1987). Effects of psychotropic drugs on conditioned defensive burying in mice. Japanese Journal of Psychopharmacology, 7, 149-150.

Vogel, J. R., BeER, B., Clody, D. E. (1971). A simple and reliable conflict procedure for testing anti-anxiety agents. Psychopharmacologia, 21, 1-7.

Yamamóto, T., UEKI, S. (1987). A new method for screening anxiolytic drugs in rats. Pharmacology, Biochemistry \& Behavior, 26. 111-117.

(Manuscript received December 31, 1987; revision accepted for publication May 13, 1988.) 